tude the profession must take toward the newly discovered "emmenagogue."

First, we are told that "titanium is found in several mineral species, in combination with magnetic iron ores. It is of a red color, and resembles copper. It is used to some extent in the arts." (Neither of the two latter statements, by the way, is true.) "Carbonate of titanium is made by double decomposition of sulphate of titanium and carbonate of sodium. It is a reddish-browi powder of a disagreeable, bitterish taste, partly soluble in water." This volunteered information is highly interesting, especially to one who has keenness enough to read between the lines. Its cunning blending of truth with fiction shows consummate genius in the perpetrator of this most daring fraud. Now listen. Properties: "It is tonic, alterative, and emmenagogue. It has produced abortion in many instances, and is commonly resorted to for that purpose by reckless women, and advised by still more reckless physicians. It seems to act without producing the very alarming symptoms usually attending such cases. It has the reputation of preventing married women from becoming preguant, by its use in combination with aloes; it has surely done it in a number of cases that have come under my observation. It is generally used in domestic practice, in the form of a saturated tincture with whisky." How singular that a compound of the rare element, titanium, should first come into use as a domestic remedy, and that in the rural districts in Pennsylvania! "My attention was first called to it by its domestic use for purposes not altogether legitimate. It is a valuable remedy, and is worthy of further consideration."

Emmenagogue forsooth! Was there ever a more unblushing advertisement of a foeticide? It matters not that the drug is innocent of the active properties attributed to it ; it will be bought for illegitimate purposes, and no other. In view of this fact, I am sure that no member of the Academy will regard the carbonate of titanium with any favor or indulgence, or will fail, indeed, on all fitting occasions to denounce it as an attempt to drag the profession into association with a class of criminals whose practices we utterly abhor and condemn.

\section{A CASE ILLUSTRATING THE APPLICABILITY OF MURIATE OF COCAINE IN NASAL SURGERY.}

\author{
BY JEFFERSON BETTMAN, M.D., CHICAGO.
}

(Read before the Chicago Medical Society, Nov. II 1884.)

The introduction of muriate of cocaine will no doubt create an era in ophthalmic surgery, the glowing tributes it has already received in Europe and in the East render irrefutable its qualities as a most efficient and innocuous local anæsthetic. Both Knapp and Gruening, of New York, have already tested its action on the nasal mucous membrane, and the re- sults attained thereby fully equal those in anæsthetizing the eye. Due to the extreme scarcity of the drug in Chicago, it is only at a late hour that I have been able to obtain a small quantity and to apply it in practice. Although my actual experience, so far, has been limited to the case subjoined, the striking results attained are sufficient to fulfill my most sanguine expectations and to regard it as a most valuable adjunct in nasal surgery.

Dr. K., a physician of this city, has been under treatment for some time, suffering from asthma nervosum. Observations render it beyond doubt, that the asthma is purely reflex, induced by great hypertrophy of both inferior turbinated bones. Barring occasional obstructions to the free nasal respiration, but little discomfort is experienced during the day. A recumbent position, the warmth generated by the bedding are sufficient to produce reflexly a sudden turgescence of the turbinated bones, blocking up of the respiratory fissure, a serous discharge, and to finish the clinical picture, a culminating, violent attack of asthma. The hyperæsthesia of the nares is truiy extraordinary, the simple introduction of the speculum is painful. The doctor has to exert all his self-control to permit the mere application of the probe to the parts. Endeavors had heretofore been directed to reducing the cavernous tissue by means of the galvano-cautery. The extreme sensibility would not permit of a thorough and prolonged application of the cautery, sufficient to act upon the deeper lying structures, so the results obtained were but partially successful. Last Saturday the doctor called at my office and we resolved to apply the muriate of cocaine prior to cauterization. Gruening, according to his report, instilled the solution into the inferior meatus, the patient's head being placed accordingly.

The small quantity of the solution at hand, compelled me to adopt another method, which impressed me as being more expedient, and at the present not unworthy of consideration, as far more economical. A pledget of cotton, sufficient in bulk to occlude the inferior meatus, was soaked with 15 drops of a 4 per cent. solution of cocaine and placed in the left nostril, between the septum and enlarged turbinated bone. At intervals of five minutes, two or three drops were instilled upon the cotton in situ. At the lapse of ten minutes, the left narium was so anæsthetized as not to perceive the touch of the probe. However, as a precautionary measure, I only removed the cotton at the expiration of a quarter of an hour. The anæsthesia of the parts was now so profound, that the gentleman could hardly give credence to my assurances that I had thoroughly and vigorously probed the parts. In marked contrast was the undiminished sensibility of the right nostril ; the introduction of the probe compelling him to cry out lustily. Previous cauterization had been made with the flat, surface electrodes, our aim, however, being to destroy the underlying cavernous tissue, we resolved to use a sharp, cutting point which had been made according to my design by Dr. McIntosh, of this city. The plates of the battery (a large Bruns battery

1 Medical Record, November $1,1884$. 
composed of two elements) were immersed sufficiently to produce a white heat when connections were made. The electrode was introduced and applied for fully three seconds ere calling forth any expression of pain on the part of the patient. As the doctor assured me. the discomfort was so minimum as hardly to be dignified with the title "pain." A striking proof of the almost total painlessness of the application, is the fact that our hitherto sensitive colleague permitted me to make another prolonged application at the same sitting. The action of the cautery was so thorough, that I am certain its ultimate results will far eclipse the benefit derived from the previous, more superficial applications. After a period of 25 minutes, the sensibility was fully restored. The doctor now began to experience the slight soreness that is always felt after cautery.

More extended observation, I trust, will tend to confirm the results already obtained and to strengthen faith in this remarkable anæsthetic. The range of its applicability is so wide, that it is nearly impossible to predestine its possibilities. It is certainly not irrelevant to state here, that its use in nasal surgery will probably enhance the popularity of galvanocautery, and increase the field of utility of this most serviceable and effective mode of treatment.

I 3 Adams St.

\section{UNILOCULAR OVARIAN CYST, WEIGHING NINETY-FIVE POUNDS, SUCCESS- FULLY REMOVED.}

BY GEO. E. RANNEY M.D., LANSING, MICH.

The following case is one of interest for a number of reasons, and especially so on account of the size of the tumor, which, as far as I know, is the largest of the kind ever removed, while few tumors of any variety have exceeded it in weight. A case (occurring in a negro woman) of fibro-cyst of the uterus, weighing I 30 pounds, including seventy-one pounds of fluid drawn from the cyst, six days before the death of the patient, together with the solid portion of the tumor, and twenty-four pounds of fluid removed after death, is reported by Dr. C. C. Stockard, of Miss., in the New York Med. Record, Aug. I 6, i 884, concerning which he says it is, as far as he can learn, the largest one on record. In this case the question may arise as to whether the most of the twenty-four pounds removed on post-mortem did not accumulate during the six days following the tapping.

Thomas, on the Diseases of Women, p. 543 , second edition, says: "The unilocular tumor consists of simple dilatation of a Graafian follicle. This may go on until the size of the uterus in the eighth or ninth month of pregnancy is reached. Kiwisch has met with one whose contents weighed forty pounds, but such a development is exceedingly rare, as they seldorn remain simple after passing the dimeusions of an adult head." Further on he says of multilocular cysts: "The size to which these cysts will grow is truly wonderful. It has been already stated that uni- locular or monocystic tumors rarely attain a great size as such; they become, as they increase, multilocular or polycystic, and then their growth may become excessive. Instances are on record of tumors containing over one hundred pounds of fluid."

Our distinguished countryman, Dr. Emmet, in his "Principles and Practice of Gynæcology," second edition, p. 826, reports the removal of a multilocular tumor weighing seventy-nine pounds, and adds: "This was the largest ovarian tumor I have ever removed."

The case in question was in the person of Mrs. T., of Grand Ledge, Mich., a native of Michigan, æt. 55 years, married, and the mother of two sons, aged tespectively 30 and 34 years. Her frame is below medium size, and up to 40 years of age she never weighed over 90 pounds. At about this age she became very fleshy, and weighed over 200 pounds. Her menopause occurred at the age of 45 years. At about the age of 49 years she discovered that the enlargement of her abdomen was more marked, and she experienced an uncomfortable fullness of it, and thought she felt through its thick walls an unnatural growth or accumulation, which led her to think she required medical assistance, and accordingly she selected her advisers from a "covey," or "brood," of ignorant homoopathic practitioners, such as afflict most of the towns of our beautiful State, where they are hatched out in as little time as it would take an egg to incubate, and where the law recognizes no difference between them and the most skillful physicians.

Her case wa; diagnosed by them a; one of abdominal dropsy, and the patient labored under that delusion, and was treated for dropsy, up to within six weeks prior to my first visit, when Dr. Wright, of Grand I.edge, an intelligent practitioner, was called to see the case. He reports that he found her in a general anasarcous condition, which anasarca, by appropriate treatment, became somewhat diminished. About one week before I saw her, and nearly two weeks before the operation, the doctor had attempted paracentesis with a medium-sized trocar, but only surceeded in drawing away a small quantity of strawcolored fluid and a thick gelatinous material of about the same color.

I was called to see her, with Dr. Wright, Oct. 2, I 884, and found her truly a sight to behold. Her abdomen was enormously distended, and its walls firmly stretched over what I diagnosed at the time, and what subsequently proved to be, a monocystic tumor of left ovary. The tumor had pressed the rectal muscles apart at the umbilicus, causing a hernial protrusion, which looked toward the floor as she stood up, so greatly was the abdomen above it distended. There had been a constant external dripping from the puncture made with the trocar - a circumstance disagreeable to the patient and attendants.

The tumor was so large and cumbersome that the patient had been, for a long time, unable to lie on her back, and for years past, in order to change from one side to the other in bed, she had to be raised, when she would stand upon the floor and approach her bed from the opposite side. 